\title{
ESTÁGIO EM PSICOPEDAGOGIA CLÍNICA: EXPERIÊNCIAS E APRENDIZAGENS ADQUIRIDAS NO PROCESSO DE AVALIAÇÃO DIAGNÓSTICA
}

\author{
INTERNSHIP IN CLINICAL PSYCHOPEDAGOGY: EXPERIENCES AND \\ LEARNING ACQUIRED IN THE DIAGNOSTIC EVALUATION PROCESS
}

\author{
Fernando da Costa Ribeiro ${ }^{1}$ \\ Shirley dos Santos Silva ${ }^{2}$
}

\begin{abstract}
RESUMO: Nesta pesquisa considera-se a psicopedagogia clínica com o seu enfoque interdisciplinar (pedagogia, psicanálise, psicologia, epistemologia, linguística e a neuropsicologia) com o campo de atuação focado os problemas no processo de processo de aprendizagem humana com a finalidade de identificar os problemas com fins de intervenção na aplicação de métodos que possam amenizar ou superar os obstáculos que impedem o desenvolvimento da aprendizagem. Com isto questiona-se como o estágio supervisionado contribui com a formação e prática do psicopedagogo formado em curso na modalidade de educação a distância? Para responder a este questionamento tem-se como objetivo geral a analise das contribuições do estágio supervisionado na formação dos psicopedagogos clínicos em curso realizado na modalidade de educação a distância, e, como objetivos específicos, a apresentação das experiências e das aprendizagens adquiridas no processo de avaliação diagnóstica no decorrer do estágio além do proporcionar revisão e atualização da literatura pertinente ao cenário. Adota-se uma metodologia de revisão de literatura, de cunho documental, histórico, qualitativo e descritivo. Por fim, registra-se a percepção de que tanto a EA quanto a Psicopedagogia preocupam-se com as aprendizagens significativas e que favorecem as transformações de pensamento, autonomia, criticidade, criatividade e contribuir para uma nova forma de pensar, sentir e agir ao tempo em que recomenda-se atuações dos profissionais destas áreas trabalhem na perspectiva da aprendizagem significativa como prática escolar cotidiana, inserindo a dimensão da EA no currículo escolar de forma interdisciplinar.
\end{abstract}

Palavras-chaves: Psicopedagogia clínica. Avaliação diagnóstica.

ABSTRACT: In this research, clinical psychopedagogy is considered with its interdisciplinary approach (pedagogy, psychoanalysis, psychology, epistemology, linguistics and neuropsychology) with the field of action focused on the problems in the process of learning learning for the purpose of intervention in the application of methods that can soften or surpass the goals that hinder the

I Doutor, Mestre, especialista em Educação, especialista em Psicopedagogia, Pedagogo e Professor. Atua com ensino, pesquisa e extensão, na Universidade do Estado do Amapá-UEAP. Contatos: ecofernando@uol.com.br.

2 Mestre e Especialista em Educação, especialista em Psicopedagogia e Pedagoga. Atua como professora na Rede de Ensino do Estado do Amapá, na Escola Estadual Ruth de Almeida Bezerra. Contatos: 2017.shirleyss@gmail.com, 
development of learning. With this question, is it questioned how the supervised internship contributes to the formation and practice of the psychopedagogue formed in course in the distance education modality? In order to answer this question, the general objective is to analyze the contributions of the supervised internship in the training of clinical psychopedagogists in a course carried out in the distance education modality, and, as specific objectives, the presentation of the experiences and learning acquired in the process of diagnostic evaluation during the internship in addition to providing the review and updating of the literature relevant to the scenario. A literature review methodology of documentary, historical, qualitative and descriptive nature is adopted. Finally, there is a perception that both the AE and the Psychopedagogy are concerned with relevant learning and that they favor transformations in thinking, autonomy, criticism, creativity and contribute to a new way of thinking, feeling and acting at the same time. in which the actions of professionals are recommended, these areas work from the perspective of practical learning as a daily school, examining the dimension of $\mathrm{AE}$ in the school curriculum in an interdisciplinary way.

Keywords: Clinical psychopedagogy. Diagnostic evaluation.

\section{INTRODUÇÃO}

A psicopedagogia clínica tem enfoque interdisciplinar que envolve os conhecimentos da pedagogia, psicanálise, psicologia, epistemologia, linguística e a neuropsicologia, e, neste sentido o seu campo de atuação está voltado para os problemas no processo de processo de aprendizagem humana e tem como finalidade identificar os problemas com finalidade de intervir com a aplicação de métodos que possam amenizar ou superar os obstáculos que impedem o desenvolvimento da aprendizagem (BOSSA, 20II).

Devido a importância da psicopedagogia clínica para o desenvolvimento da pessoa com dificuldades de aprendizagem, é que essa pesquisa traz uma análise do estágio como parte integrante e obrigatória do currículo do curso de psicopedagogia clínica realizado na modalidade de educação a distância - EAD. Deste modo, o referido estudo partiu do seguinte problema: Como o estágio supervisionado contribui com a formação e prática do psicopedagogo formado em curso na modalidade de educação a distância?

Desta maneira tem-se como objetivo geral a analisar das contribuições do estágio supervisionado na formação dos psicopedagogos clínicos em curso realizado na modalidade de educação a distância, e, como objetivos específicos, a apresentação das experiências e das aprendizagens adquiridas no processo de avaliação diagnóstica 
no decorrer do estágio além do proporcionar revisão e atualização da literatura pertinente ao cenário.

Além do exposto a proposta também justifica-se com o registro da percepção de que tanto a EA quanto a Psicopedagogia preocupam-se com as aprendizagens significativas e que favorecem as transformações de pensamento, autonomia, criticidade, criatividade e contribuir para uma nova forma de pensar, sentir e agir ao tempo em que recomenda-se atuações dos profissionais destas áreas trabalhem na perspectiva da aprendizagem significativa como prática escolar cotidiana, inserindo a dimensão da EA no currículo escolar de forma interdisciplinar (AUSUBEL, 2003), (VYGOTSKY, 1999) e (PELIZZARI, 2002).

Verifica-se também que, estudos sobre o estágio supervisionado em psicopedagogia tem sua importância devido ser uma experiência que reúne diversas aprendizagens, as quais favorecem a compreensão da atuação profissional, onde o aprendiz adquire conhecimentos práticos a respeito das intervenções na realidade (REGO; REGO PONTES, 2019) e (SAMPAIO, 2014), tendo a oportunidade vivenciar a aplicação de métodos, utilização de recursos e de maneira direta verifica, atua e se envolve com cada etapa realizada nos atendimentos, conforme observa-se em:

Por isso, o estágio impulsiona uma experiência ajudando ao profissional aprender a adquirir conhecimentos práticos e como lidar com a situação estudada a partir das teorias aprendidas no curso (REGO; REGO PONTES, 2019, p. 2).

Ainda segundo o que preconizam Rego e Rego Pontes (2019) enfatiza que o período de estágio, para o profissional aprendiz tem sua importância por ser o momento em que o futuro profissional aprende a colocar em prática todo o conhecimento teórico adquirido no período de formação.

Assim, entende-se que o estágio é uma ação que vai além da atividade curricular obrigatória, este representa o momento em que o aprendiz inserido no campo de atuação passa a analisar a realidade a partir das teorias. E no curso de psicopedagogia-EAD, o estágio supervisionado se torna

\section{METODOLOGIA}


Esse estudo se caracteriza como uma pesquisa de abordagem qualitativa e pesquisa aplicada. De acordo com o que preconiza Cervo e Bervian (2018), a investigação qualitativa se adequa aos estudos do campo das ciências humanas e é um caminho para desvelar as relações que são investigadas, de forma a adequar-se à investigação de que este projeto se propõe, visto que inicia interrogando, sem em seguida, leva para uma busca da compreensão do fenômeno, faz análises, tematiza e chega a resultados.

Deve-se considerar também que a pesquisa aplicada é o método que caracteriza esse estudo, pois direciona suas ações em torno de problemas existentes em dado grupo social e instituições se coaduna com a busca de compreensões e elaboração de soluções para um problema real.

Ainda de acordo com Cervo e Bervian (2018), a pesquisa aplicada, tem como objetivo "gerar conhecimentos para aplicação prática, dirigidos a solução de problemas específicos. Envolve verdades e interesses locais". Apesar de seu caráter prático, a pesquisa aplicada não desconsidera os estudos teóricos.

A pesquisa apresentada possui caráter qualitativo, do tipo descritivo e se sustentou em um estudo de caso, envolvendo a revisão bibliográfica, acompanhamento de um caso real a ser avaliado, observação direta do processo de avaliação diagnóstica em psicopedagogia clínica e elaboração de um diagnóstico hipotético.

A revisão bibliográfica consistiu em estudos de diversos materiais como livros, artigos e dissertações a fim de ampliar o conhecimento a respeito das finalidades da psicopedagogia e dos atendimentos nessa área, a fim de construir uma base de sustentação teórica-cientifica para o caso estudado.

O estudo foi desenvolvido através da observação direta da avaliação psicopedagógica da paciente. A observação direta permitiu o acompanhamento e aprendizagem, pois foi acompanhar in loco a anamnese, a aplicação de testes, o uso adequado dos materiais (jogos, brinquedos, atividades), a postura do profissional diante dos pais da paciente e como fazer a devolutiva. 
Desta maneira, para uma boa reflexão do problema da pesquisa e com fins de consolidar os objetivos expostos, geral e específicos, adota-se uma metodologia classificada como revisão de literatura (BECKER; KESTRING; SILVA, 2020), de cunho documental, histórico, qualitativo e descritivo (CERVO; BERVIAN, 2018) com lastro no publicado sobre a temática e afins de forma a consolidar pesquisa hodierna com as palavras chave da pesquisa como balizadoras nas bases de dados e publicações consultadas (BARROS; LEHFELD, 2019).

\section{APRENDIZAGENS ADQUIRIDAS NO PROCESSO DE AVALIAÇÃO DIAGNÓSTICA}

\section{I Psicopedagogia e o processo de aprendizagem}

É importante mencionar que a psicopedagogia se volta para compreensão do processo de aprendizagem, bem como a identificar os aspectos que interferem no curso normal da aprendizagem dos estudantes. Assim, o estágio supervisionado em psicopedagogia aqui relatado teve como foco a observação do processo de avaliação diagnóstica.

Nessa perspectiva, quando o psicopedagogo realizar o diagnóstico terá como fazer a síntese diagnóstica, que é o resultado das hipóteses levantadas em todas as sessões realizadas com o sujeito em que irá formular uma única hipótese a partir de todos os dados obtidos no diagnóstico, ou seja, é neste momento que o profissional terá que saber a causa principal do problema de aprendizagem da criança (REGO; REGO PONTES, 2019, p. 6).

O estágio supervisionado, mesmo sendo integrante de um curso EAD, proporcionou situações adequadas para que o aluno de psicopedagogia de EAD pudesse confrontar suas dúvidas e conhecimentos teóricos com a realidade no campo de atuação real do psicopedagogo, tento a oportunidade de ampliar seu repertório teórico-prático sobre as causas e possíveis intervenções nos casos de dificuldades de aprendizagens.

Vale lembrar que a psicopedagogia clínica se desenvolve com a sequência bem ordenada de várias sessões. Sendo assim, esse estudo seguiu um roteiro de observação das sessões referentes ao processo de avaliação diagnóstica que ocorreu em nove etapas durante o estágio supervisionado, as quais estão representadas na Figura I a seguir: 
Figura I: Percurso da avaliação diagnóstica realizada no estágio.

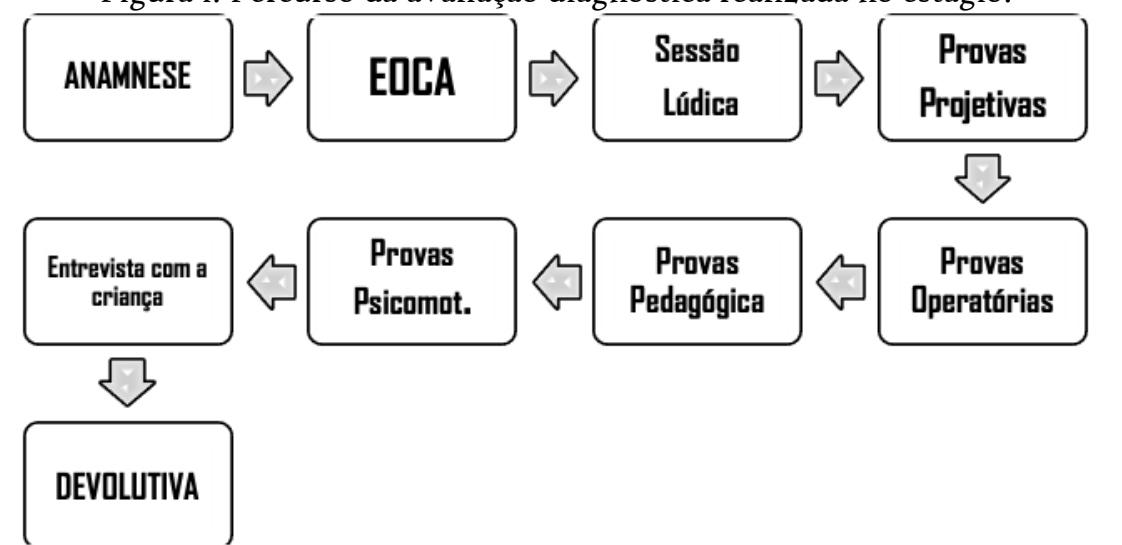

Fonte: Percurso elaborado pela professora do estágio Psicopedagoga Daniele Dias, 2020.

\subsection{Anamnese}

A primeira etapa do estágio foi a anamnese. Então, é importante a definição em torno do conceito e quais seus fins. De acordo com o que preconiza Oliveira (2018) e Oliveira (2020) o termo anamnese vem do grego onde NAMNESE corresponde a memória e ANAN significa retrocesso. Dessa maneira, pode-se compreender anamnese como o ato de conhecer a história de vida do cliente (retrocesso), tendo como objetivo coletar informações importantes sobre o cliente que ajudam a conhecer melhor essa pessoa (OLIVEIRA, 2018) e (OLIVEIRA, 2020).

Weiss (1999) apud Oliveira (2018) ressalta que não se pode realizar anamnese para "classificar o paciente em determinadas categorias". Esse processo ajuda o psicopedagogo conhecer de forma ampla os desvios que ocorrem na aprendizagem, como o cliente aprende e o precisa ser feito para superação do problema.

Segundo Sampaio (2014) a anamnese segue um roteiro de perguntas que investigam sobre os aspectos sociais incluindo a relação familiar e a escola, comportamentais, emocionais e de aprendizagem do cliente.

No estágio, não poderia ser diferente do que propõe Sampaio (2014) e Oliveira (2018), ou seja, de conhecer o cliente primeiramente através da anamnese. Para tanto, a entrevista foi norteada por um formulário elaborado pela professora-supervisora do estágio e aplicado pelos estagiários. 
O formulário investigou sobre a história do cliente, seus problemas e sua relação com o meio. Fatores importantes para traçar o plano de intervenção para o cliente.

3.3 Entrevista Operativa Centralizada Na Aprendizagem (EOCA)

Foi observado que $\operatorname{Dias}^{3}$ (2020), explicou aos estagiários que a entrevista Operativa Centralizada na Aprendizagem - EOCA, é o momento que o cliente faz atividades espontâneas, nesse momento o psicopedagogo formula seu primeiro sistema de hipóteses.

Para tanto, são ofertados materiais diversificados ao cliente em avaliação, como jogos, massinhas, livros, gibis, papel em branco com pauta e sem pauta, canetas coloridas, lápis, borracha, apontador, régua entre outros. o psicopedagogo mantém a postura de observador e precisa anotar os comportamentos do cliente durante a interação com os materiais.

\subsection{Sessão Lúdica - Hora do Jogo}

No campo psicopedagógico e educacional são apresentados vários estudos em torno da importante função dos jogos no aspecto cognitivo, tem suas contribuições tanto para auxiliar na aprendizagem, como apresenta elementos cognitivos para uma avaliação psicopedagógica.

Por estas razões, o jogo não pode ser visto apenas como divertimento e seu uso na avaliação psicopedagógica contribui no levantamento de dados sobre a situação cognitiva do paciente (SILVA, 2019).

Durante a sessão lúdica foi possível observar comportamentos que expressam o cognitivo, o afetivo e o social do indivíduo. Como também, durante o jogo pode-se observar as dificuldades do(a) paciente nas áreas cognitivas, sociais e emocionais.

Dessa maneira o estágio proporcionou a compreensão de que a hora do jogo não apenas um momento de diversão, mas um importante recurso para identificar comportamentos que precisam ser trabalhados ou desenvolvidos. A Figura 2

\footnotetext{
${ }^{3}$ Dias (2020) se refere aos conteúdos apresentados através de slides utilizados nas aulas da Profa. Daniele Dias.
} 
apresenta um roteiro de observação ${ }^{4}$ utilizado em uma sessão lúdica, conforme se observa a seguir:

Figura 2: Sessão lúdica - Roteiro de observação.

\begin{tabular}{|c|c|c|c|c|c|}
\hline \multicolumn{6}{|c|}{ HORA DO JOGO/SESSÃO LÚDICA } \\
\hline \multicolumn{6}{|l|}{ Jogo 1} \\
\hline \multicolumn{6}{|l|}{$J_{0} 02$} \\
\hline \multicolumn{6}{|l|}{$\mathrm{Jog} 03$} \\
\hline \multicolumn{6}{|l|}{$\mathrm{J}_{\mathrm{J}} \mathrm{g} 04$} \\
\hline \multicolumn{6}{|c|}{ Observaçōes: } \\
\hline Jogo & Acert & & Errou & $\begin{array}{l}\text { Compressão dos } \\
\text { comandos/regras }\end{array}$ & Dificuldades \\
\hline \multicolumn{6}{|l|}{1} \\
\hline \multicolumn{6}{|l|}{2} \\
\hline \multicolumn{6}{|l|}{3} \\
\hline \multirow{2}{*}{\multicolumn{6}{|c|}{\begin{tabular}{l|l|l|l}
4 & & & \\
\multicolumn{3}{|c|}{ Comportamentos observados durante o jogo: }
\end{tabular}}} \\
\hline & & & rvados $\mathrm{C}$ & o jogo: & \\
\hline \multicolumn{6}{|c|}{ Motivaçẵo } \\
\hline \multicolumn{6}{|c|}{ Frustraç̃ăo } \\
\hline \multicolumn{6}{|c|}{ Indiferença } \\
\hline \multicolumn{6}{|c|}{ Comemoração } \\
\hline \multicolumn{6}{|c|}{ Agressividade } \\
\hline \multicolumn{6}{|c|}{ Irritabilidade } \\
\hline \multicolumn{6}{|c|}{ Aspectos cognitivos durante o jogo: } \\
\hline & & & esentou & ades & Não apresentou dificuldades \\
\hline \multicolumn{6}{|c|}{ Atenção } \\
\hline \multicolumn{6}{|c|}{ Percepção } \\
\hline \multicolumn{6}{|c|}{ Concentração } \\
\hline \multicolumn{6}{|c|}{ Memória } \\
\hline \multicolumn{6}{|c|}{ Raciocínio } \\
\hline Inteli & & & & & \\
\hline
\end{tabular}

Fonte: Roteiro de observação elaborado pela professora do estágio Psicopedagoga Daniele Dias 2020.

É de extrema importância que o profissional deixe bem claro as regras do jogo e só fazer interferências quando perceber que a criança precisa de ajuda. $O$ profissional deve fazer elogios, estimular a(o) paciente a manter o foco na atividade $e$ sempre anotar os resultados e respostas dadas pelo cliente.

\subsection{Provas Projetivas}

Para aplicação e análise das provas projetivas foram utilizados os testes e orientações de Jorge Visca5. Projeção é o mecanismo de defesa no qual se atribui ao outro algo que é ameaçador ao sujeito, afastando-se do conflito. Sendo assim, as provas projetivas servem para visualizar aquilo que o(a) paciente se nega a identificar em si mesmo. Estes testes são aplicados para analisar as variáveis emocionais positivas ou negativas vinculadas a aprendizagem. As provas projetivas

${ }^{4}$ É proibida a reprodução do roteiro de observação da sessão lúdica apresentado nesse artigo. Este roteiro é de uso exclusivo da Profa. Psicopedagoga Daniele Dias.

5 Jorge Visca, psicólogo argentino (1935-2000), foi o principal divulgador da Psicopedagogia no Brasil. Apresentou estudos sobre aprendizagem fazendo a relação entre o cognitivo, relações interpessoais e emocionais, assim, elaborou vários testes para avaliação diagnóstica. 
ajudam a conhecer as significações que o paciente dar ao ato de aprender (VISCA, 2015).

Deve-se registrar também que, no decorrer do estágio foi observado a aplicação das provas projetivas através da realização dos seguintes testes: Teste do Par Educativo, Teste da Família e o Teste Livre.

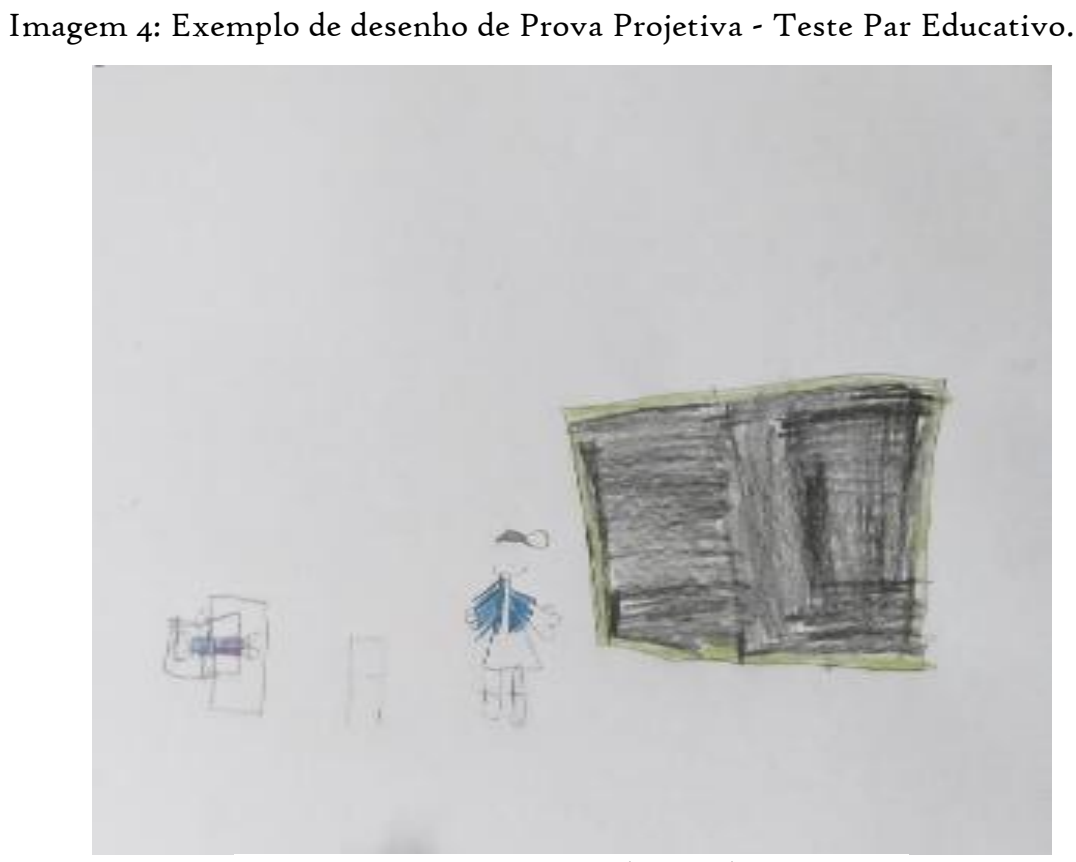

Fonte: Estagiários autores deste relatório, 2020.

O Teste do Par Educativo, que tem como objetivo identificar como o paciente internalizou o processo de aprender e a imagem que construiu a respeito daquele que ensina e o que aprende; o Teste da Família, cujo objetivo é de avaliar como se dá o relacionamento da família como um todo e o Teste Livre que tem como objetivo observar o que faz sentido emocional e concreto no a dia da criança, com ele, podemos conhecer um pouco mais as áreas de interesse dela no contexto socioafetivo (JANSSEN, 2015).

Sendo assim, na imagem 4, a paciente descreveu que desenhou o quadro da sala de aula, a professora próxima ao quadro e no lado esquerdo do papel ela se desenhou em sua mesinha assistindo aula. Usando um roteiro baseado em Jorge Visca, a terapeuta fez as seguintes análises do desenho: 
Imagem 5: Principais observações do desenho de Prova Projetiva - Teste Par Educativo.

\begin{tabular}{|c|l|l|}
\hline INDICADORES & CARACTERÍSTICAS & \multicolumn{1}{|c|}{ SIGNIFICADOS } \\
\hline Tamanho total & Desenho razoável & $\begin{array}{l}\text { Relação equilibrada. Vínculos positivos } \\
\text { e negativos equilibrados. }\end{array}$ \\
\hline $\begin{array}{c}\text { Posições } \\
\begin{array}{c}\text { Distância entre } \\
\text { os } \\
\text { de aprendizagem }\end{array}\end{array}$ & Frente a frente & Bom vínculo com a aprendizagem \\
\hline $\begin{array}{c}\text { Âmbito onde } \\
\text { se dá a cena. }\end{array}$ & $\begin{array}{l}\text { Quem ensina usa os conteúdos como } \\
\text { instrumentos para ensinar e aprender. }\end{array}$ \\
\hline Observação: Boa vinculação com a escola e aprendizagem. & $\begin{array}{l}\text { Centrada na aprendizagem sistemática. } \\
\text { Pode ser positivo ou negativo }\end{array}$ \\
\hline
\end{tabular}

Fonte: Registros profissionais de Dias (2020) durante uma avaliação diagnóstica.

Em relação a segunda etapa da realização das provas projetivas, foi aplicado o Família Educativa de Jorge Visca, cujo objetivo foi de avaliar o relacionamento de da paciente com sua família.

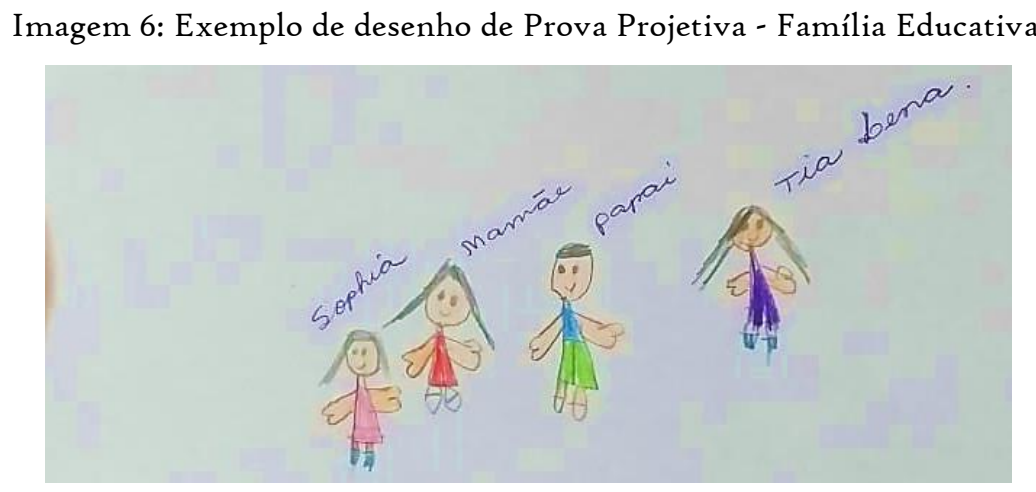

Fonte: Estagiários autores deste relatório, 2020.

A paciente relatou que seu desenho representa sua família feliz. A terapeuta por sua vez, levando em consideração os significados do desenho apresentados por Jorge Visca, observou que a criança representou através do desenho que "sente que o grupo familiar serve de referência para desenvolver e integrar modelos de aprendizagem". Assim, interpreta-se que a criança demonstra "boa vinculação familiar".

\subsection{Provas Operatórias}

As provas operatórias consistem em sessões baseadas nos testes piagetianos. Esses testes são chamados de testes de inteligência padronizados para crianças, os quais verificam em qual nível está à estrutura cognitiva do indivíduo. Para que a prova seja aplicada o psicopedagogo deve ter formação teórica, experimental e 
agilidade; ter uma postura de aceitação e acolhimento, um "olhar" que permita interpretar o comportamento apresentado (DIAS, 2020).

Durante o estágio foram aplicados os testes piagetianos ordenados de acordo com a idade da paciente ( 8 anos), a saber: Conservação (matéria, comprimento, líquido, peso); Classificação para observar a capacidade da paciente no processo de inclusão e intersecção de classes e a Seriação.

No teste de seriação, foi apresentado um jogo de palitos amarelos em tamanhos diferentes que formariam uma escala em ordem decrescente em tamanho. A paciente apresentou dificuldade na tarefa. No teste de classificação, ficou evidente que a paciente não teve dificuldades para classificar por cores, formados e quantidades.

\subsection{Provas pedagógicas}

De acordo com Souza (2013) as provas pedagógicas colaboram com a observação das habilidades da pessoa no que refere ao nível linguístico e lógico matemático. Ou seja, com as provas pedagógicas, o terapeuta tem respostas a respeito do paciente no que se refere ao uso da linguagem escrita e falada, a funcionalidade da escrita, ao nível de leitura e escrita que o paciente se encontra, a habilidade ou dificuldade para resolução de situações-problemas.

Em relação a leitura e escrita foram realizadas diversas atividades com a paciente, as quais permitiram identificar que a criança se encontra no nível silábicoalfabético. As principais atividades realizadas foram: atividade de associação de letras, sílabas e seus respectivos sons e imagens, interpretação de texto a partir da escuta de histórias (a paciente ouviu histórias por ainda não ter o domínio da leitura)

Os testes na área da linguagem escrita e da leitura demonstraram que a paciente ainda não está alfabetizada, conhece a maioria das letras, mas nem todas consegue associar aos sons e imagens correspondentes, como também ainda não consegue ler sem ajuda nem mesmo palavras dissílabas.

A prova pedagógica de matemática verificará o desenvolvimento cognitivo, demonstrando a criatividade e a coordenação motora. Em contrapartida, a prova pedagógica de português observará a conduta do sujeito numa expressão global em que se está pondo em foco o 
nível pedagógico, porém estarão juntos o seu funcionamento cognitivo e suas emoções (SOUZA, 2013, p. 4).

Dessa maneira, o estágio contribuiu para verificação e aprendizagem a respeito da aplicação, importância e objetivos das provas pedagógicas, pois os testes de matemática e linguística que foram aplicados demonstraram com clareza o nível de alfabetização da cliente, assim como, foi possível identificar suas habilidades para interpretar textos e resolver problemas que envolvem as quatro operações matemáticas.

\subsection{Provas Psicomotoras}

No site NeuroSaber, a psicopedagoga Brites (2019) apresenta o seguinte significado para a palavra psicomotricidade: psi: significa aspectos emocionais; co se refere aos aspectos cognitivos; motric tem como sinônimo o movimento humano; idade representa as etapas de vida do ser humano. Desse modo a psicomotricidade é a "ciência que busca fazer a conexão dos aspectos emocionais, cognitivos e motores nas diversas etapas da vida do ser humano" (BRITES, 2019).

Partindo do pressuposto acima, compreende-se que a prova de psicomotricidade em psicopedagogia é importante por fazer uma avaliação da relação entre os aspectos afetivos, cognitivos e do movimento.

Conhecer o desenvolvimento desses aspectos proporciona uma melhor avaliação da condição do paciente, pois a psicomotricidade orienta na condução de problemas que o paciente apresenta, demonstra questões relacionadas a autoestima, capacidade sensorial e proporciona o conhecimento de características individuais da criança (BRITES, 2019).

Durante o estágio foi possível compreender que as provas psicomotoras são atividades que possibilitam identificar se a criança apresenta um desenvolvimento psicomotor adequado para sua idade, pois dar respostas em relação a noção espacial, coordenação motora, lateralidade, compreensão dos comandos, se tem sinais de ansiedade, estes aspectos estão relacionados ao ato de aprender. 


\subsection{Entrevista com a criança}

Após a aplicação de todos os testes, foi realizada a entrevista com a paciente. Momento em que a psicopedagoga mostrou aos estagiários um roteiro de perguntas abertas para sondar a paciente sobre suas opiniões.

Dessa maneira, os estagiários percebem a forma de abordar o paciente e as questões que devem abordadas, que devem ser sobre situações a respeito do ambiente escolar, interação com parentes e amigos. Através da entrevista com a paciente é possível obter em relação parental, relação com a escola, ao futuro profissional e o qual relação que a paciente estabelece com a aprendizagem.

\section{1o Devolutiva}

O estágio demonstrou que para finalizar o processo de avaliação diagnóstica psicopedagógica, deve ser realizada a devolutiva. Ficou evidente que este momento é muito esperado pelos responsáveis da criança.

A devolutiva é a ação que aponta os procedimentos necessários para que seja resolvido ou melhorado o desenvolvimento do paciente nos aspectos pedagógicos e sociais.

Segundo Carvalho (2009), no site Recanto das Letras, diz que a devolutiva "é um documento organizado por escrito, comunicando o desenvolvimento de determinado processo de análise e avaliação diagnóstica”.

Carvalho (2009) também explica que na devolutiva devem estar descritas as dificuldades e potencialidades do paciente nos aspectos emocionais, cognitivos, pedagógicos e motores. Esse documento também deve mencionar os possíveis atendimentos que o precisa como: psicopedagogia, fonoaudiologia, clínica pediátrica, neurologia, psicoterapia.

Após a finalização do processo diagnóstico e já com a Hipótese Diagnóstica formulada é feito o agendamento da reunião destinada à devolutiva. Este documento é entregue à pessoa/pessoas ou equipe que encaminhou, apontou, discorreu, ilustrou, ou apresentou a "queixa" da dificuldade de aprendizagem do educando, criança ou jovem. (CARVALHO, 2009). 
Assim, durante o estágio os psicopedagogos em formação observaram que a devolutiva deve ser feita com muita cautela, atenção aos detalhes dos dados obtidos nos testes realizadas durante a avaliação, para que não haja erros na identificação dos problemas, fato que implicaria em todo o processo de intervenção.

\section{CONSIDERAÇÕES FINAIS}

A presente pesquisa alcançou seu propósito geral que foi de relatar o estágio vivenciada no curso de pós-graduação, psicopedagogia institucional e clínica. Mesmo que o curso tenha sido realizado na modalidade de educação a distância, o referido estágio foi uma experiência que possibilitou aos estagiários conhecerem, diretamente no campo de atuação, como se procede o processo de avaliação diagnóstica na psicopedagogia clínica,

Dessa maneira o estágio proporcionou significativas aprendizagens, pois foi o viés que uniu a teoria estudada na modalidade a distância com a prática, permitindo que os profissionais em formação pudessem vivenciar e aprender na prática o que dizem os autores dos testes aplicados na avaliação diagnostica em psicopedagogia.

Conclui-se que o aluno de psicopedagogia clínica na modalidade a distância, agrega conhecimentos teóricos necessários para atuação prática, sendo que da mesma maneira que os alunos de cursos presenciais, os alunos de EAD precisam do estágio supervisionado para consubstanciar forte contribuição da sua formação através das práticas implementadas no estágio supervisionado consolidando assim análise objetivada bem como registro de importante contribuição do estágio supervisionado alem de somar experiências e aprendizagens fortalecendo os processos de avaliação diagnóstica.

O estágio também foi fonte de conhecimento a respeito da postura do terapeuta diante dos pais da criança e da criança (paciente), de como conduzir as atividades, do ambiente (consultório) e dos materiais que devem ser disponibilizados para que a psicoterapia seja realizada de modo eficiente.

Portanto, diante da experiência vivida descrita considera-se o estágio como ação de grande importância para a atuação dos futuros psicopedagogos, ao tempo em 
que registra-se esta contribuição como legado desta pesquisa e recomenda-se aprofundamentos futuros com vistas a suplantar as suas incompletudes.

\section{REFERÊNCIAS BIBLIOGRÁFICAS}

AUSUBEL, D. P. Aquisição e retenção de conhecimentos: Uma perspectiva cognitiva, Lisboa: Editora Plátano. 2003.

BARROS, A J. P. de; LEHFELD, N. de S. Fundamentos da metodologia: um guia para iniciação científica. São Paulo: Makron. 2019.

BECKER, L. da S.; KESTRING, S.; SILVA, M. D. da. Elaboração e apresentação de trabalhos de pesquisa. Blumenau: Acadêmica Publicações. 2020.

BOSSA, Nádia A. A psicopedagogia no Brasil: contribuições a partir da prática. Porto Alegre: Artmed, 2007.

BRITES, Luciana. Quais São os Aspectos Psicomotores? Revista eletrônica NEUROSABER. Disponível em: http://neurosaber.com.br. Acesso em: 13 ago 2020.

CARVALHO, Seilla Regina Fernandes de. Uma Hipótese Diagnótica: Elementos de um Informe Psicopedagógico. Artigo eletrônico: Site Recanto das Letras, 2009. Disponível em: http://recantodasletras.com.br/artigos/1688725. Acesso em: io ago 2020.

CERVO, L.; BERVIAN, P. Metodologia científica. 9ํㅗ. ed. São Paulo: McGraw-Hill. 2018.

DIAS, Daniele. Avaliação Psicopedagógica. Slides apresentados na Faculdade FATECH. Macapá-AP. 2020.

JANSSEN, Daniela. Provas Projetivas no Diagnóstico Psicopedagógico. Site Daniela Janssen, Campinas. 2015. Disponível em https://danielajanssen.com.br/3sessao-psicopedagogica-passo-a-passo. Acesso em: I dez 2020.

OLIVEIRA, E. M. O Que fazer Interdisciplinar. In: A Educação Ambiental: uma possível abordagem. Brasília, Edições IBAMA, 2000.

OLIVEIRA, Gilmar. A Investigação Psicopedagógica Inicial: a anamnese como base do diagnóstico eficaz. Jornal da Educação - JE ISSN 2596-223X, ANO I - № oI, 
Joeinville-SC,2018. Disponível em: https://www.jornaldaeducacao.inf.br/artigoscientificos. Acesso em: Io ago 2020.

PELIZZARI, Adriana et al. Teoria da aprendizagem significativa segundo Ausubel. Rev. PEC, Curitiba, v.2, n.I, p.37-42, jul.-2001-jul. 2002. Disponível em http://files.gpecea-usp.webnode.com.br/200000393-74efd75e9b/MEQII-2013. Acesso em: 19 dez 2020.

REGO, M.S.A.; REGO PONTES, M.M.L. A Importância do Estágio Supervisionado Clínico para a Atuação do Psicopedagogo. Revista Eletrônica Holos, Ano 35, v.6, e5515, 2019. Disponível em: http://www.holos.com.br. Acesso em: ro ago 2020 .

SAMPAIO, S. Manual Prático do Diagnóstico Psicopedagógico Clínico- $5^{\underline{a}}$ Edição, Rio de Janeiro, RJ: Wak. 2014.

SILVA, Shirley dos Santos. Oficina Pedagógica para Docentes em Formação: concepção de jogos educativos para alunos com dislexia. Dissertação de Mestrado. 2019. PPGCIMES/ UFPA. Belém-PA.

SOUZA, Elson Santos de. Breve Análise de Caso em Psicopedagogia Clínica. XI Congresso Nacional de Educação. Curitiba-PR. 2013. Disponível em https://educere.bruc.com.br/. Acesso em: 13 ago 2020.

VISCA, Jorge. Técnicas Projetivas Psicopedagógicas e Pautas Gráficas Para Sua Interpretação. 6․ Edição (Português). Susana Rozenmacher (Editor) Jacqueline Glaser (Tradutor). Editora Visca \& Visca. 2018.

VYGOTSKY, L. S. A Formação Social da Mente. São Paulo: Martins Fontes, 1999 